\title{
Relationship between p53 status and the bioeffect of ionizing radiation (Review)
}

\author{
XIAOHAN KONG ${ }^{1 *}$, DEHAI YU ${ }^{2 *}$, ZHAOYI WANG $^{3 *}$ and SIJIE LI ${ }^{1 *}$ \\ ${ }^{1}$ Department of Breast Surgery, The First Hospital of Jilin University, Changchun, Jilin 130021; \\ ${ }^{2}$ Laboratory of Cancer Precision Medicine, The First Hospital of Jilin University, Changchun, Jilin 130061; \\ ${ }^{3}$ Department of Gastrointestinal Surgery, China-Japan Union Hospital of Jilin University, Changchun, Jilin 130033, P.R. China
}

Received April 18,2021; Accepted June 30, 2021

DOI: $10.3892 / 01.2021 .12922$

\begin{abstract}
Radiotherapy is widely used in the clinical treatment of cancer patients and it may be used alone or in combination with surgery or chemotherapy to inhibit tumor development. However, radiotherapy may at times not kill all cancer cells completely, as certain cells may develop radioresistance that counteracts the effects of radiation. The emergence of radioresistance is associated with the genetic background and epigenetic regulation of cells. p53 is an important tumor suppressor gene that is expressed at low levels in cells. However, when cells are subjected to stress-induced stimulation, the expression level of p53 increases, thereby preventing genomic disruption. This mechanism has important roles in maintaining cell stability and inhibiting carcinogenesis. However, mutation and deletion destroy the anticancer function of p53 and may induce carcinogenesis. In tumor radiotherapy, the status of p53 expression in cancer cells has a close relationship with radiotherapeutic efficacy. Therefore, understanding how p53 expression affects the cellular response to radiation is of great significance for solving the problem of radioresistance and improving radiotherapeutic outcomes. For the present review, the literature was searched for studies published between 1979 and 2021 using the PubMed database (https://pubmed.ncbi.nlm.nih.gov/) with the following key words: Wild-type p53, mutant-type p53, long non-coding RNA, microRNA, gene mutation, radioresistance and radiosensitivity. From the relevant studies retrieved,
\end{abstract}

Correspondence to: Professor Sijie Li, Department of Breast Surgery, The First Hospital of Jilin University, 1 Xinmin Street, Changchun, Jilin 130021, P.R. China

E-mail: lisij@jlu.edu.cn

Dr Zhaoyi Wang, Department of Gastrointestinal Surgery, China-Japan Union Hospital of Jilin University, 126 Xiantai Street, Changchun, Jilin 130033, P.R. China

E-mail: wangzhaoyi@jlu.edu.cn

${ }^{*}$ Contributed equally

Key words: p53 gene, tumor, ionizing radiation, gene mutation, long non-coding RNA, microRNA the association between different p53 mutants and cellular radiosensitivity, as well as the molecular mechanisms of p53 affecting the radiosensitivity of cells, were summarized. The aim of the present study was to provide useful information for understanding and resolving radioresistance, to help clinical researchers develop more accurate treatment strategies and to improve radiotherapeutic outcomes for cancer patients with p53 mutations.

\section{Contents}

1. Introduction

2. $\mathrm{p} 53$ and malignant disease

3. $\mathrm{p} 53$ states and radiosensitivity

4. p53 mutant sites and radiosensitivity

5. Mutant p53 and its target genes

6. p53-microRNA interaction in radiotherapy

7. 53-IncRNA interaction in radiotherapy

8. Conclusions and prospects

\section{Introduction}

In 1979, multiple laboratories simultaneously discovered a highly expressed $\sim 53 \mathrm{kDa}$ protein in cancer cells and named this protein the $\mathrm{p} 53$ protein. Initially, the $\mathrm{p} 53$ gene was considered an oncogene $(1,2)$, but it was later demonstrated to be a tumor suppressor gene by several groups $(3,4)$.

The role of p53 as a tumor suppressor gene is mainly realized through the transcriptional regulatory mechanism of apoptosis and senescence. Under normal conditions, wild-type p53 (p53 ${ }^{\mathrm{wt}}$ ) in cells is maintained at a low level due to its interaction with the E3 ubiquitin ligase MDM2. However, once DNA is damaged by radiation, the ataxia telangiectasia mutated (ATM) gene may be activated and ATM directly or indirectly phosphorylates p53 (5-8). In this circumstance, the p53 protein is subjected to numerous posttranslational modifications, such as phosphorylation, acetylation, ubiquitination, SUMOylation, neddylation and methylation. These modifications inhibit p53 from binding to MDM2, making p53 a stable transcription factor that binds to specific DNA sequences, transactivates multiple target genes [such as p21, Bax and 
p53-upregulated modulator of apoptosis (PUMA)], repairs DNA through homologous recombination and maintains the integrity of the genome (9-11). In addition, p53 also inhibits the inflammatory response (12), repairs broken DNA double strands (13) and maintains metabolic homeostasis (14).

p53 function depends on its structure. The p53 protein is composed of three major domains. The $\mathrm{N}$-terminal domain is related to the transactivation capacity of $\mathrm{p} 53$, and it is a disordered and inherently unfolded region consisting of a trans-activated domain and a proline-rich region. The central domain is the key component of p53, controlling the sequence-specific DNA-binding activity of p53 and promoting the DNA-p53 protein interaction. This region is also the most susceptible to mutations, which are known to occur in $>90 \%$ of human cancers. The $\mathrm{C}$-terminal domain is also a disordered structural domain that controls the posttranslational modification activity of p53 (15).

\section{2.p53 and malignant disease}

The p53 protein status is correlated with the p53 gene status. Cancer cells may have three different p53 gene states: $\mathrm{p} 53^{\mathrm{wt}}$, mutant-type $\mathrm{p} 53\left(\mathrm{p} 53^{\mathrm{mt}}\right)$ and $\mathrm{p} 53$ deletion (null-type p53 or p53 $\left.{ }^{\text {null }}\right)$ (16). p53 mutation is common, occurring in $\sim 50 \%$ of human cancers $(17,18)$. The most common and well-characterized p53 mutations are missense mutations (75\%). Other alterations include frameshift insertion and deletion (9\%), nonsense mutation (7\%), silent mutation (5\%) and rare changes $(19,20)$. $\mathrm{p}^{\mathrm{m}} 3^{\mathrm{mt}}$ gene encodes $\mathrm{p} 53^{\mathrm{mt}}$ protein. $\mathrm{P} 53^{\mathrm{mt}}$ prevents apoptosis and promotes the proliferation and metastasis of cancer cells (21). p53 ${ }^{\text {mt }}$ deactivates sequence-specific DNA-binding activity, thereby causing the loss of normal p53 tumor suppressor function and the inability of the p53 heterodimer to form a tetramer complex, thereby damaging dimer function (22). In addition, $\mathrm{p} 53^{\mathrm{mt}}$ causes another 'gain of function' (GOF) that not only promotes tumor progression, migration and metabolism but also increases tumor cell resistance to radiotherapy $(23,24)$. This outcome is ascribed to the upregulation of multiple genes by $\mathrm{p} 53^{\mathrm{mt}}$, including phosphatase and tensin homolog, c-myc, NF- $\mathrm{kB}, \mathrm{p} 16^{\mathrm{INK} 4 \mathrm{~A}}$, p63 and p73 (25-30).

Studies have also indicated that certain tumors have p53 ${ }^{\text {null }}$ status (31). The absence of p53 leads to failure of G1-S checkpoint blockade, making tumors more resistant to radiotherapy (32).

In general, cancer cells carrying $\mathrm{p} 53^{\mathrm{wt}}$ are more sensitive to radiation than cells carrying $\mathrm{p} 53^{\mathrm{mt}}$ or $\mathrm{p} 53^{\text {null }}(6,33,34)$. An in-depth understanding of the relationship between p53 and radiosensitivity will help enhance the efficacy of radiotherapy and improve the prognosis of patients.

\section{3. p53 states and radiosensitivity}

Radiotherapy is one of the most common cancer treatments and it may be used in combination with chemotherapy or surgery to treat various malignant tumor types (35). Radiation kills tumor cells by causing DNA damage. Once DNA damage is identified, cellular sensor proteins, such as ATM, deliver damage signals to effectors and phosphorylate certain targets, such as p53 (7).
Radioresistance is a key factor limiting radiotherapeutic efficacy (36). Several cellular signaling pathways and factors are involved in radioresistance, such as the p53-p21 and p53-Bcl-2 pathways (37,38). Among these pathways, the p53 pathway is considered the most crucial regulator $(39,40)$.

$p 53^{m t}$ and radioresistance. The mechanism by which p53 ${ }^{\mathrm{mt}}$ causes radioresistance was first proposed by Brachman et al (41) when they irradiated head and neck squamous cell carcinoma and determined that $\mathrm{p} 53^{\mathrm{mt}}$ cells were more resistant to radiation than $\mathrm{p} 53^{\mathrm{wt}}$ cells. This result was also verified by Hinata et al (42), who used bladder cancer cell lines to demonstrate that $\mathrm{p} 53^{\mathrm{wt}}$-mediated cell cycle arrest in G1 phase increases radiosensitivity. Similarly, Williams et al (43) reported that the radioresistance of $\mathrm{p} 53^{\mathrm{mt}} \mathrm{Li}-\mathrm{Fraumeni}$ syndrome fibroblast cells is associated with reduced G1 phase-blocking ability.

However, certain studies have suggested that $\mathrm{P} 53^{\mathrm{mt}}$ may increase radiosensitivity (44). Biard et al (45) established four types of rat lung epithelial cells to test cell survival after radiation exposure and showed that the survival rate of p5 $3^{\mathrm{mt}}$ cells is significantly lower than that of other cell lines. Kawashima et al (46) observed a similar phenomenon and speculated that this outcome is attributed to $\mathrm{P}^{2} 3^{\mathrm{mt}}$ being unable to induce cell cycle arrest, indicating that $\mathrm{p} 53^{\mathrm{mt}}$ cells are more susceptible to DNA damage than $\mathrm{p} 53^{\mathrm{wt}}$ cells.

$p 53^{w t}$ and radiosensitivity. Numerous cytological experiments have indicated that $\mathrm{p} 53^{\mathrm{wt}}$ cells are more radiosensitive than $\mathrm{p} 53^{\mathrm{mt}}$ cells $(42,47)$. By assessing the survival rate of human ovarian cancer cell lines irradiated by $12 \mathrm{~Gy}{ }^{60} \mathrm{Co}$ rays, Concin et al (48) demonstrated that $\mathrm{p} 53^{\mathrm{wt}}$ cells were more radiosensitive than $\mathrm{p} 53^{\mathrm{mt}}$ cells with cell survival rates of 0.4 and 0 , respectively. In agreement with the above study, Cheng et al (49) determined that radiation-induced apoptosis was significantly higher in $\mathrm{p} 53^{\mathrm{wt}}$ than in $\mathrm{p} 53^{\mathrm{mt}}$ lung cancer cells. In addition, Pirollo et al (50) indicated that the introduction of $553^{\mathrm{wt}}$ increased the radiosensitivity of $\mathrm{p} 53^{\text {null }}$ cells. In vivo experiments have also confirmed this result. Gallardo et al (51) introduced $\mathrm{p} 53^{\mathrm{wt}}$ and $\mathrm{p} 53^{\mathrm{mt}}$ into $\mathrm{p} 53^{\text {null }}$ mice and then subjected the mice to irradiation, and they reported that tumor growth was slower in $\mathrm{p} 53^{\mathrm{wt}}$ mice than in $\mathrm{p} 53^{\mathrm{mt}}$ mice.

p53 $3^{\text {null }}$ and radiosensitivity. Certain studies have indicated that $\mathrm{p} 53^{\text {null }}$ cells are more radiosensitive than $\mathrm{p} 53^{\mathrm{wt}}$ cells. Servomaa et al (52) compared the survival of head and neck tumor cells with different p53 states and determined that cells with a loss of p53 were more sensitive to $\gamma$-irradiation, suggesting that a p53-independent apoptosis pathway may be triggered in these cells during radiotherapy.

However, opinions on this mechanism are contradictory. p53 $3^{\text {null }}$-associated radioresistance is also observed in tumor cells. Lowe et al (53) injected three types of tumor cells with different p53 variants into rats and irradiated tumor-burdened rats, and they indicated that the tumors in $\mathrm{p} 53^{\text {null }}$ rats were larger and that the apoptotic cell number was significantly lower in $\mathrm{p} 53^{\mathrm{wt}}$ rats. Merritt et al (54) and Matsui et al (55) also determined that p53 deletion prompts cell radioresistance. It is speculated that this radioresistance is generally considered to involve the inhibition of p53-dependent apoptosis. 
Other hypotheses and clinical trials. Certain studies have suggested that $\mathrm{p} 53^{\mathrm{mt}}$ is not associated with radioresistance $(56,57)$. Tchelebi (34) suggested that the differences are correlated with the genetic background of the cell lines and the type of p53 mutation. Certain clinical investigations have focused on p53 mutants and radiation efficacy. Tada et al (58) suggested that $\mathrm{p} 53^{\mathrm{mt}}$ may prolong the survival rate of cancer patients receiving radiotherapy. Koch et al (59) determined that after radiotherapy, the overall survival of patients carrying p5 $3^{\mathrm{mt}}$ cells was not affected, but they exhibited a risk of regional recurrence.

\section{4. p53 mutant sites and radiosensitivity}

Although p53 mutations are observed in the whole gene, there are six mutation hotspots distributed in the DNA-binding domain. These six hotspots are located in codons 175, 245, 248, 249, 273 and 282 (60). Different p53 mutation types may lead to distinctly different cellular functions and effects on radiotherapeutic efficacy even when the mutations are in the same domain. Menendez et al (61) indicated that different p53 mutations produce different cellular phenotypes after transfection, leading to cell survival or apoptosis. After cells are exposed to radiation, the expression levels of target genes, such as p21, MDM2, Bax and mutS homolog 2, which correlate with the cell cycle and cell apoptosis, induced by different $\mathrm{p} 53^{\mathrm{mt}}$ mutants are different; therefore, the biological activities of these transfectants are completely different. Okaichi et al (62) transferred four types of mutant p53 genes distributed separately at codons 123 ( Thr $\rightarrow$ Ala), 143 (Val $\rightarrow$ Ala), 175 (Arg $\rightarrow$ His) and 273 (Arg $\rightarrow$ His) into human osteosarcoma Saos-2 cells (p53 ${ }^{\text {null }}$ ) and irradiated the cells with X-rays. The results indicated that the radiosensitivity of cells expressing mutant p53 proteins $(123 \mathrm{Thr} \rightarrow \mathrm{Ala})$ is higher than that of cells expressing proteins with other mutation types, while the expression of p53 proteins mutated at amino acids 143, 175 and 273 does not affect cellular radiosensitivity. In addition, the same group performed a similar experiment with 12 different types of p53 mutations and determined that mutations in hotspots may cause loss of p53 binding ability to DNA and, thus, loss of transcription function. However, mutations in loop domains do not change the conformation of the p53 protein and its normal functions are retained. They also demonstrated that mutations occurring at the $\mathrm{N}$-terminus of the p53 protein affect downstream p21 ${ }^{\mathrm{WAF} 1}$ expression and radiosensitivity $(63,64)$.

\section{Mutant p53 and its target genes}

p5 $3^{\mathrm{mt}}$ alters the normal intracellular pathway and functions through interactions with various factors and enhances the radioresistance of cancer cells by inhibiting apoptosis or promoting repair. Elucidation of the relationship between these genes and $\mathrm{p} 53^{\mathrm{mt}}$ may enhance the understanding of tumorigenesis and discover additional methods to treat tumors.

Radiation disrupts the DNA structure and activates certain protein kinase pathways, which block cell cycle progression and initiate DNA repair processes. p53 is the major downstream effector in DNA damage-activated kinase pathways and the main role of p53 is to promote cellular apoptosis induced by radiation. Activated p53 triggers G1 phase arrest by transactivating $\mathrm{p} 21^{\text {Waf } 1}$, allowing cells additional time for DNA repair (65). In addition, p53 upregulates the proapoptotic molecules PUMA and NADPH oxidase activator 1, and activates the $\mathrm{Bcl}$ family member Bax to promote the apoptosis of nonrepairable cells and the recovery of tissue homeostasis (66).

In the case of p53 mutations, p53 ${ }^{\mathrm{mt}}$-mediated transactivation, cell cycle arrest and apoptosis responses may be abrogated. Furthermore, $\mathrm{p} 53^{\mathrm{mt}}$ accelerates the rate of tumor proliferation and induces radio/drug resistance (67-70). This mechanism of resistance may be attributed to the regulation of $\mathrm{p} 53^{\mathrm{mt}}$. MYC is a major mediator of mutant p53 GOF in head and neck squamous cell carcinoma (HNSCC), leading to radioresistance and a high local recurrence rate of HNSCC. Recruitment of $\mathrm{p} 53^{\mathrm{mt}}$ to the MYC promoter increases MYC stability and continuous expression (71). Ganci et al (72) demonstrated that inhibition of the $\mathrm{p} 53^{\mathrm{mt}} / \mathrm{MYC}$-dependent signature alters the radiosensitivity of HNSCC cells. Cellular inhibitor of PP2A (CIP2A) activates various oncogenic proteins and promotes the proliferation of various cancer cells. p53 inhibits the expression of CIP2A. Kim et al (73) indicated that CIP2A modulates the radioresistance of cancer cells by attenuating cell senescence in HNSCC through disruption caused by $\mathrm{p} 53^{\mathrm{mt}}$. They irradiated HNSCC cell lines carrying different p53 mutants to determine their effects on cell survival and CIP2A expression levels, and they observed that CIP2A is highly expressed in radioresistant HNSCC cells carrying disruptive p53 ${ }^{\mathrm{mt}}$. Inhibition of CIP2A enhances the radiosensitivity of these $\mathrm{p} 53^{\mathrm{mt}}$-disrupted cells. Nitric oxide (NO) synthase 2 (NOS2) produces high levels of NO, acting as either a cytotoxic or a cytoprotective agent. Matsumoto et al (74) indicated that after irradiation of human glioblastoma cell lines carrying $\mathrm{p} 53^{\mathrm{mt}}$, NO is upregulated by $\mathrm{p} 53^{\mathrm{mt}}$. In addition, upregulated NO expression led to the increased accumulation of p53 in p53 ${ }^{\mathrm{wt}}$-transfected cells through the intercellular signaling/transduction pathway. These results suggested that the reduced radiosensitivity may be attributed to the increased cell survival rate caused by the presence of p53-triggered cancer cell repair during NO-induced G1-phase arrest.

\section{6. p53-microRNA interaction in radiotherapy}

miRNAs constitute a class of small noncoding RNA molecules involved in the regulation of multiple cell behaviors, such as gene expression, cell division, differentiation, apoptosis, metabolism and cancer development (75-77). The communication of miRNAs with various signaling factors provides an ingenious entry point for improving the efficacy of radiotherapy. Further understanding the role of miRNAs in tumor radiosensitivity, particularly their relationship with p53, is helpful for forming novel ideas to solve the ubiquitous radiation resistance problem in cancer treatment and for providing more effective therapeutic strategies for patients who are suitable for radiotherapy.

p53 and miRNA interactions have key roles in modulating the cellular response to radiation. For instance, p53 induces the expression of miR-34 in cells with DNA damage and overexpression of miR-34 enhances radiosensitivity $(78,79)$. miRNAs bind to the 3'UTR of p53 mRNA and suppress p53 translation, negatively regulating p53-related genes, 
Table I. Summary of the history of p53 research and the association between p53 expression and radiation response.

$\begin{array}{ll}\text { Item Details and (Refs.) } & \text { Defor }\end{array}$

p53 discovery

p53 function

$\mathrm{p} 53^{\mathrm{mt}}$ and radiation

$\mathrm{p} 53^{\mathrm{wt}}$ and radiation

$\mathrm{p} 53^{\text {null }}$ and radiation

p53-associated pathways in radiation

p53-miRNA interaction in radiotherapy

p53-IncRNA interactions in radiotherapy
Misidentification as an oncogene $(1,2)$

Role as a tumor suppressor gene $(3,4)$

p53 structure $(15,18,19,21,63)$

Regulators of p53 (5-8)

Target genes of p53 (9-11,21,24-29,60,64,65,70-72)

p53 and the inflammatory response (12), DNA double-strand breaks (13)

and metabolic homeostasis (14)

p5 $3^{\mathrm{mt}}$ increases radioresistance $(22,23,40-42)$

p5 $3^{\mathrm{mt}}$ increases radiosensitivity $(43-45,61)$

p5 $3^{\mathrm{wt}}$ increases radiosensitivity $(32,33,41,46-50)$

p5 $3^{\text {null }}$ increases radioresistance $(31,52-54)$

p5 $3^{\text {null }}$ increases radiosensitivity $(44,51)$

p53-p21 pathway (36)

p53-Bcl-2-caspase pathway (37)

p53 induces the expression of miR-34 and enhances radiosensitivity $(76,77)$

miR-375 regulates p53 expression and reduces radiosensitivity (78)

miR-300 reduces radiosensitivity by inducing p53 (79)

miR-375 inhibits p53 degradation and increases radiosensitivity (82)

Let-7 decreases the radiosensitivity of p53 $3^{\mathrm{wt}}$ cells (86)

IncRNA ROR increases radioresistance by inhibiting p53 (90)

IncRNA CCAT2 promotes radioresistance by inhibiting p53 (91)

p53 modulates radiation-induced cellular apoptosis by regulating

IncRNA Trp53cor1 and Tug1 (92)

p53 ${ }^{\mathrm{mt}}$, mutant p53; p53 ${ }^{\mathrm{wt}}$, wild-type p53; p53 ${ }^{\text {null }}$, p53 deletion; lncRNA, long non-coding RNA; miR/miRNA, microRNA; CCAT2, colon cancer-associated transcript 2; Trp53cor1, tumor protein p53 pathway corepressor 1; Tug1, taurine-upregulated 1; ROR, regulator of reprogramming.

such as p21 and MDM2, and inducing cell cycle arrest and radioresistance. Liu et al (80) reported that the presence of miR-375, which is associated with the recurrence of gastric cancer, reduces the radiosensitivity of tumor cells by regulating the expression of $\mathrm{p} 53$. He et al (81) observed that in human lung cancer cells, radiation upregulates the expression level of miR-300 and reduces radiosensitivity by inducing p53/apaf1-related G2-phase cell cycle arrest and apoptosis. By contrast, miRNAs may stimulate the expression of p53 and increase tumor radiosensitivity $(82,83)$. Song et al $(84)$ indicated that in patients with cervical cancer, miR-375 is overexpressed after radiotherapy. miR-375 inhibits the degradation of p53 and leads to cell cycle arrest in G1-phase, thereby increasing radiosensitivity.

Radiation-induced p53 overexpression also inhibits the level of miRNAs and negatively affects radiation efficacy (85). miRNA let-7 family members function differently in different cells after irradiation (86). One of the targets of let-7 is KRAS, which induces radioresistance (87). In certain cancer cells, miRNAs such as let-7a and let-7b (let-7 family members) are inhibited after irradiation and their inhibition is correlated with $\mathrm{p} 53^{\mathrm{wt}}$ expression. Saleh et al (88) irradiated $\mathrm{p} 53^{\text {null }}$ and $\mathrm{p} 53^{\mathrm{wt}}$ mouse colon cancer cell lines and observed that let-7 decreases the radiosensitivity of $\mathrm{p} 53^{\mathrm{wt}}$ cells but not $\mathrm{p} 53^{\text {null }}$ cells. In addition, experiments have revealed that functional p53

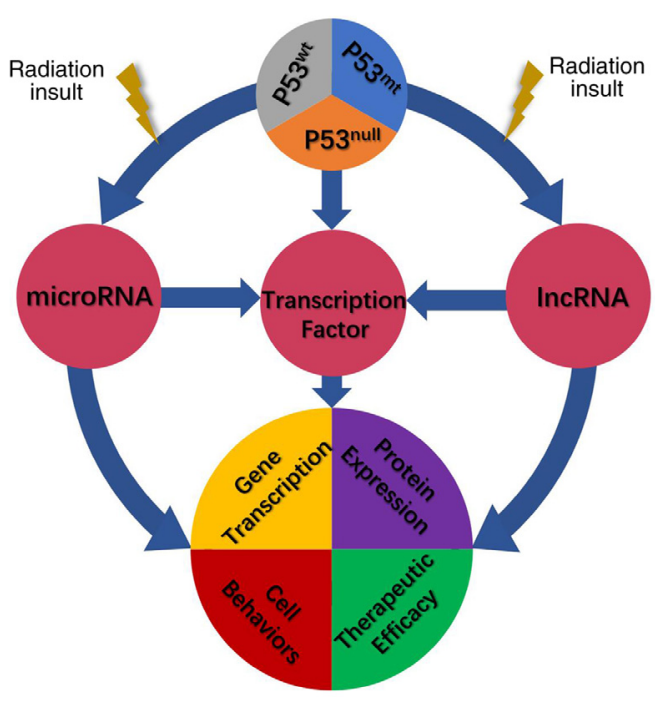

Figure 1. Schematic of the molecular mechanisms of $\mathrm{p} 53$ regulating radiation response. $\mathrm{p} 53^{\mathrm{mt}}$, mutant $\mathrm{p} 53$; $\mathrm{p} 53^{\mathrm{wt}}$, wild-type $\mathrm{p} 53$; $\mathrm{p} 53^{\text {null }}$, p53 deletion; lncRNA, long non-coding RNA.

directly interacts with Drosha, a miRNA-processing enzyme, and inhibits the expression of let-7a and let-7b through transcriptional regulation in cells after irradiation. 


\section{7. p53-IncRNA interaction in radiotherapy}

LncRNAs constitute a class of noncoding RNAs with a length of $>200 \mathrm{bp}$ that have regulatory roles in chromatin modification, transcription and posttranscriptional gene regulation. An increasing number of lncRNAs have been indicated to have important roles in the development and treatment of tumors. This increase in lncRNAs may be used as a cancer marker to detect specific diseases and improve the rate of early diagnosis of tumors (89).

LncRNAs are involved in various mechanisms in cells to regulate radiosensitivity, such as DNA damage repair, cell cycle arrest and apoptosis. LncRNA and p53 interactions may regulate cellular radiosensitivity. Zhang et al (90) and Wang et al (91) indicated that lncRNAs participate in the nonhomologous end joining pathway after radiation-induced DNA damage, which accelerates damage repair and reduces radiation sensitivity. Yang et al (92) reported that the IncRNA regulator of reprogramming (ROR) increases radioresistance in colorectal cancer cells by inhibiting the p53/miR-145 axis, which is known to be an important pathway for tumor inhibition; they determined that the levels of p53 protein and miR-145, as well as the degree of radiosensitivity of colorectal cells, are increased after X-ray irradiation compared to lncRNA ROR-deficient cells. In esophageal cancer, Wang et al (93) observed that IncRNA colon cancer-associated transcript 2 promotes radioresistance by inhibiting the $\mathrm{p} 53$ proapoptotic signaling pathway. Beer et al (94) indicated that p53 has a central role in the modulation of radiation-induced cellular apoptosis by regulating the expression of several lncRNAs, including tumor protein p53 pathway corepressor 1 (Trp53cor1) and taurine-upregulated (Tug1). They treated human peripheral blood mononuclear cells with high-dose $\gamma$ radiation and determined that Trp53cor1, as a downstream target of p53, was significantly upregulated after cell irradiation and that the expression of caspase- 3 was increased; they also observed that the expression level of lncRNA Tug1 in cells was increased after IR. As a downstream target gene of p53, lncRNA Tug1 increases cell radiosensitivity by promoting cell cycle arrest and apoptosis through the regulation of various miRNAs, including miR-222-3p, miR-221-3p, miR-132 and miR-29a.

\section{Conclusions and prospects}

Over the past 40 years, with the enhanced understanding of the structure, role and mutations of the p53 tumor suppressor gene, it has become increasingly evident that p53 has an important role in tumor inhibition and treatment, and its importance underlies the carcinogenicity of its deletion or mutation. Deletion or mutation of p53 in tumor cells leads to the loss of normal p53 antitumor function and promotes the occurrence and metastasis of cancer. Summary of the research results of the past 30 years supports that the antiapoptotic properties of $\mathrm{p} 53^{\mathrm{mt}}$ enhance tumor resistance to radiotherapy, which inhibits the efficacy of cancer treatment. The p53 status, to a certain degree, may be considered as a useful biomarker for radiosensitivity, and it is advocated to elevate the irradiation dose, prolong the irradiation time, or select a more suitable treatment strategy, i.e. chemotherapy, targeted therapy and immunotherapy for those patients with $\mathrm{p} 53^{\mathrm{mt}}$.

Identifying the mechanism of $\mathrm{p} 53$ in promoting radioresistance may help doctors develop accurate treatment strategies for patients and improve the radiotherapeutic outcomes and prognosis for patients. As part of the present study, a summary of the history of p53 research and the association between p53 expression and radiation response (Table I) and a schematic of the mechanisms related to p53 and radioresistance (Fig. 1) are provided. Specifically, the role of non-coding RNAs in p53-induced radioresistance was summarized, which is rarely mentioned in previous reports and similar reviews. The present review is an extension and supplement to the traditional theories. It is esteemed that these mechanisms serve as a basis to guide further analysis, laboratory studies and clinical practice for cancer patients receiving radiotherapy.

\section{Acknowledgements}

Not applicable.

\section{Funding}

This work was supported in part by the Subject Arrangement Program from the Science and Technology Department of Jilin Province (grant nos. 20190201209JC to SL and 20200201123JC to DY).

\section{Availability of data and materials}

Data sharing is not applicable.

\section{Authors' contributions}

DY and SL contributed to the conception and design of the article. XK drafted the manuscript. ZW drafted the figure and table and revised the manuscript. All authors have read and approved the final manuscript. Data authentication is not applicable.

\section{Ethics approval and consent to participate}

Not applicable.

\section{Patient consent for publication}

Not applicable.

\section{Competing interests}

The authors declare that they have no competing interests.

\section{References}

1. Lane DP and Crawford LV: T antigen is bound to a host protein in SV40-transformed cells. Nature 278: 261-263, 1979.

2. Linzer DI and Levine AJ: Characterization of a $54 \mathrm{~K}$ dalton cellular SV40 tumor antigen present in SV40-transformed cells and uninfected embryonal carcinoma cells. Cell 17: 43-52, 1979.

3. Eliyahu D, Michalovitz D, Eliyahu S, Pinhasi-Kimhi O and Oren M: Wild-type p53 can inhibit oncogene-mediated focus formation. Proc Natl Acad Sci USA 86: 8763-8767, 1989. 
4. Baker SJ, Fearon ER, Nigro JM, Hamilton SR, Preisinger AC, Jessup JM, vanTuinen $\mathrm{P}$, Ledbetter DH, Barker DF, Nakamura Y, et al: Chromosome 17 deletions and p53 gene mutations in colorectal carcinomas. Science 244: 217-221, 1989.

5. Canman CE, Lim DS, Cimprich KA, Taya Y, Tamai K, Sakaguchi K, Appella E, Kastan MB and Siliciano JD: Activation of the ATM kinase by ionizing radiation and phosphorylation of p53. Science 281: 1677-1679, 1998.

6. Sun Q, Guo Y, Liu X, Czauderna F, Carr MI, Zenke FT, Blaukat A and Vassilev LT: Therapeutic implications of p53 status on cancer cell fate following exposure to ionizing radiation and the DNA-PK inhibitor M3814. Mol Cancer Res 17: 2457-2468, 2019

7. Cui D, Xiong X, Shu J, Dai X, Sun Y and Zhao Y: FBXW7 confers radiation survival by targeting p53 for degradation. Cell Rep 30: 497-509.e4, 2020.

8. Venkata Narayanan I, Paulsen MT, Bedi K, Berg N,Ljungman EA Francia S, Veloso A, Magnuson B, di Fagagna FD, Wilson TE and Ljungman M: Transcriptional and post-transcriptional regulation of the ionizing radiation response by ATM and p53. Sci Rep 7: 43598, 2017.

9. Marcel V, Catez F and Diaz JJ: p53, a translational regulator: Contribution to its tumour-suppressor activity. Oncogene 34: 5513-5523, 2015

10. Shirai Y, Shiba H, Iwase R, Haruki K, Fujiwara Y, Furukawa K, Uwagawa T, Ohashi T and Yanaga K: Dual inhibition of nuclear factor kappa-B and Mdm2 enhance the antitumor effect of radiation therapy for pancreatic cancer. Cancer Lett 370: 177-184, 2016.

11. Bechill J, Zhong R, Zhang C, Solomaha E and Spiotto MT: A high-throughput cell-based screen identified a 2-[(E)-2Phenylvinyl]-8-quinolinol core structure that activates p53.PLoS One 11: e0154125, 2016.

12. Uehara I and Tanaka N: Role of p53 in the regulation of the inflammatory tumor microenvironment and tumor suppression. Cancers (Basel) 10: 219, 2018

13. Menon V and Povirk L: Involvement of p53 in the repair of DNA double strand breaks: Multifaceted Roles of p53 in homologous recombination repair (HRR) and non-homologous end joining (NHEJ). Subcell Biochem 85: 321-336, 2014.

14. Moulder DE, Hatoum D, Tay E, Lin Y and McGowan EM: The roles of p53 in mitochondrial dynamics and cancer metabolism: The pendulum between survival and death in breast cancer? Cancers (Basel) 10: 189, 2018.

15. Fischbach A, Krüger A, Hampp S, Assmann G, Rank L, Hufnagel M, Stöckl MT, Fischer JMF, Veith S, Rossatti P, et al: The C-terminal domain of $\mathrm{p} 53$ orchestrates the interplay between non-covalent and covalent poly(ADP-ribosyl)ation of p53 by PARP1. Nucleic Acids Res 46: 804-822, 2018.

16. Kamp WM, Wang PY and Hwang PM: TP53 mutation, mitochondria and cancer. Curr Opin Genet Dev 38: 16-22, 2016.

17. Zhu G, Pan C, Bei JX, Li B, Liang C, Xu Y and Fu X: Mutant p53 in cancer progression and targeted therapies. Front Oncol 10: 595187, 2020.

18. Long S, Loureiro JB, Carvalho C, Gales L, Saraiva L, Pinto MMM, Puthongking P and Sousa E: Semi-synthesis of small molecules of aminocarbazoles: Tumor growth inhibition and potential impact on p53. Molecules 26: 1637, 2021.

19. Olotu FA and Soliman MES: Dynamic perspectives into the mechanisms of mutation-induced p53-DNA binding loss and inactivation using active perturbation theory: Structural and molecular insights toward the design of potent reactivators in cancer therapy. J Cell Biochem 120: 951-966, 2019.

20. Petitjean A, Achatz MI, Borresen-Dale AL, Hainaut P and Olivier M: TP53 mutations in human cancers: Functional selection and impact on cancer prognosis and outcomes. Oncogene 26: 2157-2165, 2007

21. Mantovani F, Collavin L and Del Sal G: Mutant p53 as a guardian of the cancer cell. Cell Death Differ 26: 199-212, 2019.

22. Milner J, Medcalf EA and Cook AC: Tumor suppressor p53: Analysis of wild-type and mutant p53 complexes. Mol Cell Biol 11: 12-19, 1991.

23. Alvarado-Ortiz E, de la Cruz-López KG, Becerril-Rico J, Sarabia-Sánchez MA, Ortiz-Sánchez E and García-Carrancá A: Mutant p53 gain-of-function: Role in cancer development, progression, and therapeutic approaches. Front Cell Dev Biol 8: 607670, 2021.

24. Li H, Zhang J, Tong JHM, Chan AWH, Yu J, Kang W and To KF: Targeting the oncogenic p53 mutants in colorectal cancer and other solid tumors. Int J Mol Sci 20: 5999, 2019.
25. Li Y, Guessous F, Kwon S, Kumar M, Ibidapo O, Fuller L, Johnson E, Lal B, Hussaini I, Bao Y, et al: PTEN has tumor-promoting properties in the setting of gain-of-function p53 mutations. Cancer Res 68: 1723-1731, 2008.

26. Zhang F, Li K, Yao X, Wang H, Li W, Wu J, Li M, Zhou R, Xu L and Zhao L: A miR-567-PIK3AP1-PI3K/AKT-c-Myc feedback loop regulates tumour growth and chemoresistance in gastric cancer. EBioMedicine 44: 311-321, 2019.

27. Vaughan CA, Singh S, Windle B, Sankala HM, Graves PR, Andrew Yeudall W, Deb SP and Deb S: p53 mutants induce transcription of NF-kB2 in $\mathrm{H} 1299$ cells through CBP and STAT binding on the NF- $\mathrm{KB} 2$ promoter and gain of function activity. Arch Biochem Biophys 518: 79-88, 2012.

28. Zhang J, Pickering CR, Holst CR, Gauthier ML and Tlsty TD: p16INK4a modulates p53 in primary human mammary epithelial cells. Cancer Res 66: 10325-10331, 2006.

29. Gaiddon C, Lokshin M, Ahn J, Zhang T and Prives C: A subset of tumor-derived mutant forms of p53 down-regulate p63 and p73 through a direct interaction with the p53 core domain. Mol Cell Biol 21: 1874-1887, 2001.

30. Lang GA, Iwakuma T, Suh YA, Liu G, Rao VA, Parant JM, Valentin-Vega YA, Terzian T, Caldwell LC, Strong LC, et al: Gain of function of a p53 hot spot mutation in a mouse model of Li-Fraumeni syndrome. Cell 119: 861-872, 2004.

31. Olivier M, Hollstein M and Hainaut P: TP53 mutations in human cancers: Origins, consequences, and clinical use. Cold Spring Harb Perspect Biol 2: a001008, 2010.

32. Marusyk A, Porter CC, Zaberezhnyy V and DeGregori J: Irradiation selects for $\mathrm{p} 53$-deficient hematopoietic progenitors. PLoS Biol 8: e1000324, 2010.

33. Wouters A, Pauwels B, Lambrechts HA, Pattyn GG, Ides J, Baay M, Meijnders P, Peeters M, Vermorken JB and Lardon F: Retention of the in vitro radiosensitizing potential of gemcitabine under anoxic conditions, in p53 wild-type and p53-deficient non-small-cell lung carcinoma cells. Int J Radiat Oncol Biol Phys 80: 558-566, 2011

34. Tchelebi L, Ashamalla H and Graves PR: Mutant p53 and the response to chemotherapy and radiation. Subcell Biochem 85: 133-159, 2014.

35. Fuentes-Orrego JM and Sahani DV: Low-dose CT in clinical diagnostics. Expert Opin Med Diagn 7: 501-510, 2013.

36. Poon DJJ, Tay LM, Ho D, Chua MLK, Chow EK and Yeo ELL: Improving the therapeutic ratio of radiotherapy against radioresistant cancers: Leveraging on novel artificial intelligence-based approaches for drug combination discovery. Cancer Lett 511: 56-67, 2021.

37. Wu C, Guo E, Ming J, Sun W, Nie X, Sun L, Peng S, Luo M, Liu D, Zhang L, et al: Radiation-induced DNMT3B promotes radioresistance in nasopharyngeal carcinoma through methylation of p53 and p21. Mol Ther Oncolytics 17: 306-319, 2020.

38. da Costa Araldi IC, Bordin FPR, Cadoná FC, Barbisan F, Azzolin VF, Teixeira CF, Baumhardt T, da Cruz IBM, Duarte MMMF and Bauermann LF: The in vitro radiosensitizer potential of resveratrol on MCF-7 breast cancer cells. Chem Biol Interact 282: 85-92, 2018.

39. Fei P and El-Deiry WS: P53 and radiation responses. Oncogene 22: 5774-5783, 2003.

40. Gudkov AV and Komarova EA: The role of p53 in determining sensitivity to radiotherapy. Nat Rev Cancer 3: 117-129, 2003.

41. Brachman DG, Beckett M, Graves D, Haraf D, Vokes E and Weichselbaum RR: p53 mutation does not correlate with radiosensitivity in 24 head and neck cancer cell lines. Cancer Res 53: 3667-3669, 1993.

42. Hinata N, Shirakawa T, Zhang Z, Matsumoto A, Fujisawa M, Okada H, Kamidono $\mathrm{S}$ and Gotoh A: Radiation induces p53-dependent cell apoptosis in bladder cancer cells with wild-type-p53 but not in p53-mutated bladder cancer cells. Urol Res 31: 387-396, 2003

43. Williams KJ, Boyle JM, Birch JM, Norton JD and Scott D: Cell cycle arrest defect in Li-Fraumeni Syndrome: A mechanism of cancer predisposition? Oncogene 14: 277-282, 1997.

44. Ribeiro JC, Barnetson AR, Fisher RJ, Mameghan $\mathrm{H}$ and Russell PJ: Relationship between radiation response and p53 status in human bladder cancer cells. Int J Radiat Biol 72: 11-20, 1997.

45. Biard DS, Martin M, Rhun YL, Duthu A, Lefaix JL, May E and May P: Concomitant p53 gene mutation and increased radiosensitivity in rat lung embryo epithelial cells during neoplastic development. Cancer Res 54: 3361-3364, 1994. 
46. Kawashima K, Mihara K, Usuki H, Shimizu N and Namba M: Transfected mutant $\mathrm{p} 53$ gene increases X-ray-induced cell killing and mutation in human fibroblasts immortalized with 4-nitroquinoline 1-oxide but does not induce neoplastic transformation of the cells. Int J Cancer 61: 76-79, 1995.

47. Weber KJ and Wenz F: p53, apoptosis and radiosensitivity-experimental and clinical data. Onkologie 25: 136-141, 2002.

48. Concin N, Zeillinger C, Stimpfel M, Schiebel I, Tong D, Wolff U, Reiner A, Leodolter S and Zeillinger R: p53-dependent radioresistance in ovarian carcinoma cell lines. Cancer Lett 150 191-199, 2000.

49. Cheng G, Kong D, Hou X, Liang B, He M, Liang N, Ma S and Liu X: The tumor suppressor, $\mathrm{p53}$, contributes to radiosensitivity of lung cancer cells by regulating autophagy and apoptosis. Cancer Biother Radiopharm 28: 153-159, 2013.

50. Pirollo KF, Hao Z, Rait A, Jang YJ, Fee WE Jr, Ryan P, Chiang Y and Chang EH: p53 mediated sensitization of squamous cel carcinoma of the head and neck to radiotherapy. Oncogene 14: $1735-1746,1997$.

51. Gallardo D, Drazan KE and McBride WH: Adenovirus-based transfer of wild-type p53 gene increases ovarian tumor radiosensitivity. Cancer Res 56: 4891-4893, 1996.

52. Servomaa K, Kiuru A, Grénman R, Pekkola-Heino K, Pulkkinen JO and Rytömaa T: p53 mutations associated with increased sensitivity to ionizing radiation in human head and neck cancer cell lines. Cell Prolif 29: 219-230, 1996.

53. Lowe SW, Bodis S, McClatchey A, Remington L, Ruley HE, Fisher DE, Housman DE and Jacks T: p53 status and the efficacy of cancer therapy in vivo. Science 266: 807-810, 1994

54. Merritt AJ, Potten CS, Kemp CJ, Hickman JA, Balmain A, Lane DP and Hall PA: The role of p53 in spontaneous and radiation-induced apoptosis in the gastrointestinal tract of normal and p53-deficient mice. Cancer Res 54: 614-617, 1994.

55. Matsui Y, Tsuchida Y and Keng PC: Effects of p53 mutations on cellular sensitivity to ionizing radiation. Am J Clin Oncol 24 486-490, 2001

56. Shi Q, Sutariya V, Varghese Gupta S and Bhatia D: GADD $45 \alpha$-targeted suicide gene therapy driven by synthetic CArG promoter E9NS sensitizes NSCLC cells to cisplatin, resveratrol, and radiation regardless of p53 status. Onco Targets Ther 12: 3161-3170, 2019.

57. Cuneo KC, Morgan MA, Davis MA, Parcels LA, Parcels J, Karnak D, Ryan C, Liu N, Maybaum J and Lawrence TS: Weel kinase inhibitor AZD1775 radiosensitizes hepatocellular carcinoma regardless of TP53 mutational status through induction of replication stress. Int J Radiat Oncol Biol Phys 95: 782-790, 2016.

58. Tada M, Matsumoto R, Iggo RD, Onimaru R, Shirato H, Sawamura Y and Shinohe Y: Selective sensitivity to radiation of cerebral glioblastomas harboring p53 mutations. Cancer Res 58 : 1793-1797, 1998

59. Koch WM, Brennan JA, Zahurak M, Goodman SN, Westra WH, Schwab D, Yoo GH, Lee DJ, Forastiere AA and Sidransky D p53 mutation and locoregional treatment failure in head and neck squamous cell carcinoma. J Natl Cancer Inst 88: 1580-1586, 1996.

60. Mello SS and Attardi LD: Not all p53 gain-of-function mutants are created equal. Cell Death Differ 20: 855-857, 2013.

61. Menendez D, Inga A and Resnick MA: The biological impact of the human master regulator $\mathrm{p} 53$ can be altered by mutations that change the spectrum and expression of its target genes. Mol Cell Biol 26: 2297-2308, 2006.

62. Okaichi K, Wang LH, Ihara M and Okumura Y: Sensitivity to ionizing radiation in Saos-2 cells transfected with mutant p53 genes depends on the mutation position. J Radiat Res 39: 111-118, 1998.

63. Okaichi K, Nose $\mathrm{K}$, Kotake T, Izumi $\mathrm{N}$ and Kudo $\mathrm{T}$ : Phosphorylation of $\mathrm{p} 53$ modifies sensitivity to ionizing radiation. Anticancer Res 31: 2255-2258, 2011.

64. Okaichi K, Ide-Kanematsu M, Izumi N, Morita N, Okumura Y and Ihara M: Variations in sensitivity to ionizing radiation in relation to p53 mutation point. Anticancer Res 28: 2687-2690, 2008

65. Mazzatti DJ, Lee YJ, Helt CE, O'Reilly MA and Keng PC: p53 modulates radiation sensitivity independent of p21 transcriptional activation. Am J Clin Oncol 28: 43-50, 2005.

66. Aubrey BJ, Kelly GL, Janic A, Herold MJ and Strasser A: How does p53 induce apoptosis and how does this relate to p53-mediated tumour suppression? Cell Death Differ 25: 104-113, 2018.

67. Brosh R and Rotter V: When mutants gain new powers: News from the mutant p53 field. Nat Rev Cancer 9: 701-713, 2009.
68. Stein Y, Rotter V and Aloni-Grinstein R: Gain-of-function mutant p53: All the roads lead to tumorigenesis. Int J Mol Sci 20: 6197, 2019.

69. Bellazzo A, Sicari D, Valentino E, Del Sal G and Collavin L: Complexes formed by mutant $\mathrm{p} 53$ and their roles in breast cancer. Breast Cancer (Dove Med Press) 10: 101-112, 2018.

70. Zhang C, Liu J, Xu D, Zhang T, Hu W and Feng Z: Gain-of-function mutant p53 in cancer progression and therapy. J Mol Cell Biol 12: 674-687, 2020

71. Huang X, Zhang Y, Tang Y, Butler N, Kim J, Guessous F, Schiff D, Mandell J and Abounader R: A novel PTEN/mutant p53/c-Myc/Bcl-XL axis mediates context-dependent oncogenic effects of PTEN with implications for cancer prognosis and therapy. Neoplasia 15: 952-965, 2013.

72. Ganci F, Pulito C, Valsoni S, Sacconi A, Turco C, Vahabi M, Manciocco V, Mazza EMC, Meens J, Karamboulas C, et al: PI3K inhibitors curtail MYC-dependent mutant p53 gain-of-function in head and neck squamous cell carcinoma. Clin Cancer Res 26 : 2956-2971, 2020

73. Kim SH, Lee WH, Seong D, An JH, Je HU, Nam HY, Kim SY, Kim SW and Han MW: The role of CIP2A as a therapeutic target of rapamycin in radioresistant head and neck cancer with TP53 mutation. Head Neck 41: 3362-3371, 2019.

74. Matsumoto H, Hayashi S, Hatashita M, Ohnishi K, Shioura H, Ohtsubo T, Kitai R, Ohnishi T and Kano E: Induction of radioresistance by a nitric oxide-mediated bystander effect. Radiat Res 155: 387-396, 2001

75. Bajan S and Hutvagner G: RNA-based therapeutics: From antisense oligonucleotides to miRNAs. Cells 9: 137, 2020.

76. Bajan S and Hutvagner G: Regulation of miRNA processing and miRNA mediated gene repression in cancer. Microrna 3: 10-17, 2014.

77. Adams BD, Parsons C, Walker L, Zhang WC and Slack FJ: Targeting noncoding RNAs in disease. J Clin Invest 127: 761-771, 2017.

78. Hermeking H: p53 enters the microRNA world. Cancer Cell 12: 414-418, 2007.

79. Balça-Silva J, Sousa Neves S, Gonçalves AC, Abrantes AM, Casalta-Lopes J, Botelho MF, Sarmento-Ribeiro AB and Silva HC: Effect of miR-34b overexpression on the radiosensitivity of non-small cell lung cancer cell lines. Anticancer Res 32: $1603-1609,2012$

80. Liu Y, Xing R, Zhang X, Dong W, Zhang J, Yan Z, Li W, Cui J and $\mathrm{Lu} \mathrm{Y}$ : miR-375 targets the p53 gene to regulate cellular response to ionizing radiation and etoposide in gastric cancer cells. DNA Repair (Amst) 12: 741-750, 2013.

81. He J, Feng X, Hua J, Wei L, Lu Z, Wei W, Cai H, Wang B, Shi W, Ding N, et al: miR-300 regulates cellular radiosensitivity through targeting p53 and apaf1 in human lung cancer cells. Cell Cycle 16: 1943-1953, 2017.

82. Xu R, Li H, Wu S, Qu J, Yuan H, Zhou Y and Lu Q: MicroRNA-1246 regulates the radio-sensitizing effect of curcumin in bladder cancer cells via activating P53. Int Urol Nephrol 51: 1771-1779, 2019.

83. Ye C, Sun NX, Ma Y, Zhao Q, Zhang Q, Xu C, Wang SB, Sun SH, Wang $\mathrm{F}$ and Li W: MicroRNA-145 contributes to enhancing radiosensitivity of cervical cancer cells. FEBS Lett 589: 702-709, 2015.

84. Song L, Liu S, Zeng S, Zhang L and Li X: miR-375 modulates radiosensitivity of HR-HPV-positive cervical cancer cells by targeting UBE3A through the p53 pathway. Med Sci Monit 21: 2210-2217, 2015

85. Kumar A and Chandna S: Evidence for a radiation-responsive 'p53 gateway' contributing significantly to the radioresistance of lepidopteran insect cells. Sci Rep 8: 2, 2018.

86. Metheetrairut C and Slack FJ: MicroRNAs in the ionizing radiation response and in radiotherapy. Curr Opin Genet Dev 23: $12-19,2013$

87. Johnson SM, Grosshans H, Shingara J, Byrom M, Jarvis R, Cheng A, Labourier E, Reinert KL, Brown D and Slack FJ: RAS is regulated by the let-7 microRNA family. Cell 120: 635-647, 2005.

88. Saleh AD, Savage JE, Cao L, Soule BP, Ly D, DeGraff W, Harris CC, Mitchell JB and Simone NL: Cellular stress induced alterations in microRNA let-7a and let-7b expression are dependent on p53. PLoS One 6: e24429, 2011.

89. Gibb EA, Brown CJ and Lam WL: The functional role of long non-coding RNA in human carcinomas. Mol Cancer 10: 38, 2011.

90. Zhang Y, He Q, Hu Z, Feng Y, Fan L, Tang Z, Yuan J, Shan W, $\mathrm{Li} \mathrm{C}, \mathrm{Hu} \mathrm{X}$, et al: Long noncoding RNA LINP1 regulates repair of DNA double-strand breaks in triple-negative breast cancer. Nat Struct Mol Biol 23: 522-530, 2016 
91. Wang X, Liu H, Shi L, Yu X, Gu Y and Sun X: LINP1 facilitates DNA damage repair through non-homologous end joining (NHEJ) pathway and subsequently decreases the sensitivity of cervical cancer cells to ionizing radiation. Cell Cycle 17: 439-447, 2018.

92. Yang P, Yang Y, An W, Xu J, Zhang G, Jie J and Zhang Q: The long noncoding RNA-ROR promotes the resistance of radiotherapy for human colorectal cancer cells by targeting the p53/miR-145 pathway. J Gastroenterol Hepatol 32: 837-845, 2017.

93. Wang M, Wang L, He X, Zhang J, Zhu Z, Zhang M and Li X: IncRNA CCAT2 promotes radiotherapy resistance for human esophageal carcinoma cells via the miR-145/p70S6K1 and p53 pathway. Int J Oncol 56: 327-336, 2020.
94. Beer L, Nemec L, Wagner T, Ristl R, Altenburger LM, Ankersmit $\mathrm{HJ}$ and Mildner M: Ionizing radiation regulates long non-coding RNAs in human peripheral blood mononuclear cells. J Radiat Res 58: 201-209, 2017.

(c) (i) $(9)$ This work is licensed under a Creative Commons cC) International (CC BY-NC-ND 4.0) License. 